\title{
PROGRAMAS DEMOS: LOS JÓVENES CON DISCAPACIDAD INTELECTUAL FORMAN PARTE DE LA COMUNIDAD UNIVERSITARIA
}

\author{
Autor: Javier Alcázar Colilla \\ jalcazar@comillas.edu \\ Universidad Pontificia Comillas
}

\begin{abstract}
Resumen
La ley garantiza a los jóvenes con discapacidad intelectual la educación obligatoria, ya sea por la vía inclusiva o por la vía especial. Pero una vez superada esta, hasta hace muy poco no existían alternativas formativas que les permitieran seguir estudiando y, especialmente, elegir su vocación. Ante la realidad excluyente a la que se enfrentaba este colectivo, la Universidad Pontificia Comillas puso en marcha hace ya siete años los Programas Formativos DEMOS, centrados en proporcionarles una alta capacitación laboral ajustada a las necesidades del mercado de trabajo y, lo que es más importante, a poder desarrollar su vocación.
\end{abstract}

Palabras clave: discapacidad intelectual; educación integrada; calidad de vida; inserción laboral; vocación. 


\title{
DEMOS Programs. Young People with Intellectual Disabilities are part of the University Community
}

\begin{abstract}
The law guarantees compulsory schooling for young people with intellectual disabilities, either through the inclusive route or through the special route. But once it has been overcome, until very recently there were no training alternatives that allowed them to continue forming and, especially, to choose their vocation. In front of this excluding reality to this group, the Pontifical Comillas University started seven years ago DEMOS Training Programs, focused on providing high work skills adjusted to the needs of the working market and, the most important thing, to allow them to develop their vocation.
\end{abstract}

Key words: intellectual disability; integrated education; quality of life; job insertion; vocation.

Fecha de recepción: 5/05/2019

Fecha de aceptación: 6/05/2019

\section{ORÍGENES}

El Programa DEMOS nació en el año 2012 de la mano de la Universidad Pontificia Comillas, con la colaboración de la Fundación Síndrome de Down de Madrid. Su objetivo principal es ofrecer formación a jóvenes con discapacidad intelectual en el entorno de la Universidad, encaminada a su futura incorporación al mundo laboral.

Los Programas se enmarcan en la actividad desarrollada por la Cátedra de Familia y Discapacidad Fundación Repsol-Down Madrid, cuyo objetivo es investigar y promover la calidad de vida y bienestar de las personas con discapacidad intelectual, así como de sus familias, desde una perspectiva multiprofesional, innovadora, crítica y comprometida con la sociedad. Algunos de los fines de la Cátedra son llevar a cabo investigaciones, desarrollar innovación de carácter científico en el ámbito de la discapacidad e impulsar actividades de formación. La Cátedra depende del Instituto Universitario de la Familia de la Universidad Pontificia Comillas.

El nombre de los Programas tiene su origen en el filósofo griego Demóstenes quien, a pesar de padecer tartamudez se sometió a una rigurosa disciplina y llegó 
a convertirse en uno de los mejores oradores y políticos de la Grecia Clásica. Su deseo de superación y su capacidad de vencer las barreras fueron el símbolo elegido para nombrar a este proyecto pionero que abre las puertas de la Universidad a aquellos alumnos cuyas características y necesidades de apoyo les han mantenido fuera de sus aulas hasta ahora.

El derecho a la vocación fue otro de los aspectos que el Programa DEMOS ha pretendido facilitar, contribuyendo a la realización personal de los jóvenes con discapacidad intelectual a través de su trayectoria formativa y profesional. Así, la Universidad Pontificia Comillas en colaboración con la Fundación Síndrome de Down de Madrid realizó un estudio entre sus jóvenes para conocer qué espacios profesionales eran los más demandados por ellos. El resultado se tradujo en la puesta en marcha de dos itinerarios diferenciados, centrados en los ámbitos educativo y tecnológico, que se abordarán más adelante.

\section{OBJETIVOS}

El objetivo central de los Programas DEMOS es la formación general y específica, desde una vertiente humanista, con objeto de favorecer una futura inclusión laboral de jóvenes con discapacidad intelectual en el entorno normalizado de trabajo. Los Programas están dirigidos a adultos con discapacidad intelectual, mayores de 18 años, que estén interesados en una formación dirigida al empleo.

Una de las bases desde el nacimiento de este proyecto fue añadir a esa formación específica los enormes beneficios que podría suponer para los jóvenes con discapacidad intelectual el compartir un espacio social, cultural y evolutivo como lo es la Universidad para muchos jóvenes.

La posibilidad de formarse durante dos años en un entorno universitario normalizado proporciona espacios de inclusión en los cuales desarrollar sus potencialidades, optimizar su perfil de empleabilidad e interactuar diariamente con otros alumnos universitarios de edades similares.

Esta convivencia cotidiana en el campus universitario de alumnos con discapacidad intelectual es una oportunidad enriquecedora para toda la comunidad docente. También para aquellos alumnos universitarios, futuros profesionales, que tendrán ocasión de compartir de primera mano las vivencias, experiencias, ilusiones y aspiraciones de estos jóvenes, aprendiendo así a convivir, gestionar y enriquecerse en la diversidad.

La formación integral y humanista es una de las señas de identidad de la Universidad Pontificia Comillas. Precisamente por ello también debe estar incluida en los itinerarios formativos de los Programas DEMOS, y esto se da a través de la participación de los alumnos en múltiples actividades culturales, deportivas o 
pastorales, así como en diversos contenidos curriculares que inciden en el desarrollo ético, creativo y cultural del alumnado.

\section{DESARROLLO}

Los diplomas formativos que existen en el programa son dos:

- Programa Formativo Técnico Auxiliar en Entornos Educativos: EDU. CADEMOS.

Este perfil capacita al joven para desempeñar diversas tareas en el entorno educativo, tanto en actividades vinculadas a la atención directa de los alumnos como a otras relacionadas con la administración y mantenimiento del centro. Le dota de competencias relacionadas con el desarrollo infantil, cuidados básicos y necesidades del niño, así como aquellas relacionadas con servicios administrativos, biblioteca y conserjería. Las salidas profesionales están en espacios como Escuelas Infantiles, Centros de Educación Primaria, Centros de Ocio, Bibliotecas y Centros de Educación Especial.

- Programa Formativo Técnico Auxiliar en Entornos Tecnológicos: TECNODEMOS: este perfil está orientado a todos aquellos jóvenes que desean trabajar en entornos más tecnológicos o de empresa. Capacita al joven para desempeñar actividades relacionadas con las nuevas tecnologías, tratamiento informático de la información, así como aquellas relacionadas con la gestión administrativa.

Cada programa formativo específico requiere de una serie de competencias mínimas adecuadas. Los principales aspectos metodológicos utilizados en el programa son:

- Contextualización y transferencia

- Formación integral y personalizada

- Aprendizaje cooperativo

- Trabajo con materiales prácticos y personalizados

En ambos casos se trata de perfiles innovadores, que superan los trabajos mayoritariamente manipulativos que vienen siendo tradicionalmente desarrollados por las personas con discapacidad intelectual en nuestro país. Se contribuye así a promover una imagen social más positiva del colectivo de personas con discapacidad intelectual. 
Uno de los objetivos fundamentales es formar a los alumnos como profesionales cualificados y competitivos de cara a su incorporación al mercado laboral. La formación integral es, por tanto, la vía más completa y adecuada para ello y el currículo formativo del Programa DEMOS se ha diseñado atendiendo a múltiples dimensiones:

a) Formación académica cualificada. Los alumnos adquieren una serie de competencias conceptuales, procedimentales y actitudinales que necesitarán para el desempeño de su actividad profesional.

b) Formación práctica y transferencia. La formación está diseñada para que los contenidos puedan ser transferidos al futuro entorno laboral, donde puedan ser puestos en práctica. Para garantizar esta área, los programas incluyen cuatro niveles de prácticas:

1. Prácticas en el aula/Universidad. Se realiza un entrenamiento en la aplicación de todas las competencias procedimentales aprovechando también los propios recursos de la Universidad en diferentes departamentos.

2. Visitas de profesionales externos. Diversos profesionales, tanto pertenecientes a empresas como independientes, visitan las aulas del programa para introducir a los alumnos en la realidad del contexto laboral para el que se preparan.

3. Visitas a empresas o centros educativos. Durante el transcurso del programa, diferentes empresas y entidades abren sus puertas a los alumnos para que puedan conocerlas por dentro, facilitando así su contacto con sus futuros entornos profesionales.

4. Prácticas externas. El programa incluye dos meses de prácticas externas, con un preparador laboral, en un centro escolar o entorno empresarial respectivamente. Las prácticas se realizan en estrecha colaboración con el Área de Empleo de la Fundación Síndrome de Down de Madrid, siguiendo la metodología de empleo con apoyo. Además de consolidar los aprendizajes, este período sirve para sensibilizar a empresas y centros educativos.

c) Formación en valores. Impulsando el deseo de reflexionar sobre los códigos éticos de los ámbitos en los que se desarrolla la persona (profesionales, sociales, legales y personales).

d) Formación integral. Además de la formación vinculada al entorno profesional, la Universidad pone a disposición actividades culturales, deportivas y pastorales. 


\section{RESULTADOS Y CONCLUSIONES}

Desde la puesta en marcha de los Programas Formativos DEMOS, 163 alumnos han pasado por sus aulas. Ello ha supuesto que, durante estos siete años, miles de alumnos, cientos de docentes y personal de la Universidad han podido convivir con jóvenes con distintas capacidades, lo que ha supuesto un enorme enriquecimiento bidireccional y un impulso a su visibilidad y participación social.

Han sido muchos los Centros Universitarios que se han interesado por estos programas y que los han conocido de primera mano, sirviendo DEMOS de modelo para el nacimiento de nuevos programas formativos para jóvenes con discapacidad en el ámbito de la Educación Superior tanto a nivel nacional como internacional.

A ello podemos sumar que, desde el inicio de la incorporación de los jóvenes con discapacidad intelectual que cursaron los Programas DEMOS al mercado de trabajo, casi 50 alumnos han conseguido incorporarse al mundo laboral, ya sea mediante contratos temporales o indefinidos. Teniendo en cuenta que, aproximadamente, el 50\% de los alumnos opta por continuar su formación en otros centros, se podría afirmar que los Programas Formativos DEMOS mejoran de manera muy significativa la empleabilidad de los jóvenes con discapacidad intelectual, además de suponer un impulso fundamental a su desarrollo personal y social.

La apuesta de la Universidad Pontificia Comillas por la diversidad y la integración ha cosechado, por tanto, un gran éxito en todos sus objetivos; con mucho camino aún por recorrer, DEMOS ha sido y seguirá siendo un referente en facilitar el desarrollo y la integración de los jóvenes con discapacidad intelectual en el ámbito universitario. 